Constancy of the volume of the assay solution is maintained during the operation of aliquoting by means of water of the same temperature as the solution running through the jacketed portion of the pipette from the tank in which the flask is immersed.

Error in weighing is minimized by the deposition of two grams of copper on an electrode of small area and weight.

With the object of preventing oxidation of the copper by the electrolyte, as high a current density is employed as is consistent with the formation of a smooth deposit.

Active circulation throughout the electrolyte is procured by electrolyzing in a glass having a concave bottom.

Account is taken of deposited impurities and correction is applied appropriate to the brands undergoing assay.

By the weekly testing of the accuracy of the delivery of the pipette and the twice-a-week assay of standard copper, the accuracy of the work is checked.

In developing the method to its present standard of excellence, I wish to acknowledge the assistance of all the laboratory staff who have contributed, but, more especially to Mr. William O'Gorman who has charge of copper determinations and Mr. F. A. Holbrook, formerly first assistant chemist.

I wish, also, to express appreciation to $\mathrm{Mr}$. W. G. Derby, present first assistant chemist, for doing most of the work of preparing this paper and for reading it before the New York Section of the American Chemical Society.

H.

\section{A RAPID METHOD FOR THE ELECTROLYTIC DETERMINATION OF COPPER IN ORES.}

\author{
BY R. C. BENNER. \\ Received March 8, 1910.
}

When the greatest possible accuracy is desired in the determination of copper, recourse is had to the electrolytic mathod. The great disadvantages in this have been either the length of time it took to make the determination in case of the ordinary method; or (when the deposition is to be quickly made), the necessity of a special piece of complex apparatus, the rotating electrode, or a solenoid. Quite recently it has been found that it is possible, by means of the gauze electrode, ${ }^{1}$ to deposit certain metals nearly as rapidly as with either of the pieces of apparatus mentioned. This gives an apparatus which is as simple and costs no more than that in ordinary use; and yet will give results with a rapidity nearly equal to those obtained with the more complicated and costly pieces.

The platinum electrode used in these determinations was corrugated and sand-blasted, cylindrical in shape,

I Stoddard, J. Am. Chem. Soc., 31, 385 (1909); Chem. Nerts, 99, 292. and about one inch in diameter by one and one-half inches long, made from fifty-two mesh wire gauze.

The accuracy was checked against $C$. P. copper foil, which had been proven to contain roo per cent. copper by the ordinary electrolytic method. The copper foil was dissolved in three cc. of nitric acid (sp. gr. I.4), diluted to seventy-five cc. with water and electrolyzed in from ten to fifteen minutes with a current of about ten amperes and four volts.

$\begin{array}{cccccc}\begin{array}{c}C u \\ \text { taken. }\end{array} & \begin{array}{c}\mathrm{Cu} \\ \text { found. }\end{array} & \begin{array}{c}\text { Volume of } \\ \text { solution. }\end{array} & \begin{array}{c}\text { Amperes. } \\ \text { Ajric }\end{array} & \begin{array}{c}\text { Nit. } \\ \text { acid. }\end{array} & \text { Time. } \\ 0.1181 & 0.1181 & 75 \mathrm{cc} . & 10-15 & 1 \mathrm{cc} . & 10 \\ 0.3586 & 0.3584 . & 75 \mathrm{cc} . & 10 & 3 \mathrm{cc} . & 12 \\ 0.2330 & 0.2332 & 75 \mathrm{cc} . & 8-10 & 3 \mathrm{cc} . & 12 \\ 0.2142 & 0.2142 & 75 \mathrm{cc} . & 8-10 & 3 \mathrm{cc} . & 15 \\ 0.2374 & 0.2375 & 75 \mathrm{cc} . & 8-10 & 3 \mathrm{cc} . & 15\end{array}$

The preceding results show that the accuracy is equal to that of the older method. The character of the deposit is all that could be asked for.

The rate of deposition under these conditions will be readily seen from the following results and a glance at the curve.

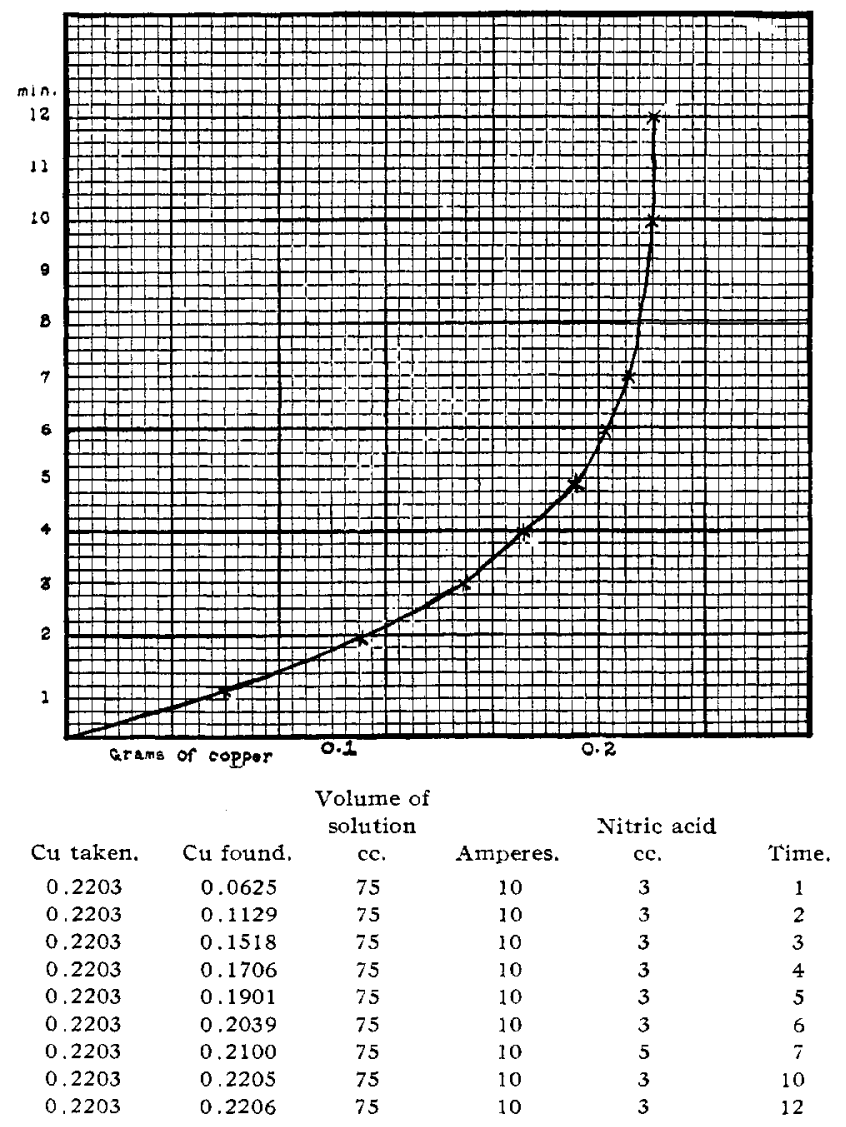

All but about seven and five-tenths per cent. is precipitated in the first five minutes, while it takes another five to complete the precipitation. This point is frequently overlooked, especially in technical work, and therefore gives rise to error.

Process for Ores.-Frcm 0.5 to 1.0 gram of the ore, which contains none of the interfering elements, is dissolved in nitric or nitric and hydrochloric acids. When 
aqua regia is used, or if lead is present, sulphuric acid is added and evaporation continued until the heavy white fumes of sulphuric anhydride are evolved. The excess of sulphuric acid is neutralized with ammonia and three cc. of concentrated nitric acid added.

Providing sulphuric acid is not added it is only - necessary to concentrate to three cubic centimeters. In either case the solution is diluted to $75 \mathrm{cc}$, transferred to a tall battery beaker, without being filtered (if the residue does not settle it is better to filter) and the copper deposited by means of a current of 8 to Io amperes and 3 to 4 volts. If the deposit is black or dark colored it is dissolved in nitric acid and redeposited in the same way. This redeposition is, as a rule, easier and quicker than filtering. The following results show the accuracy of this method on ores, as compared with those obtained by the older method.

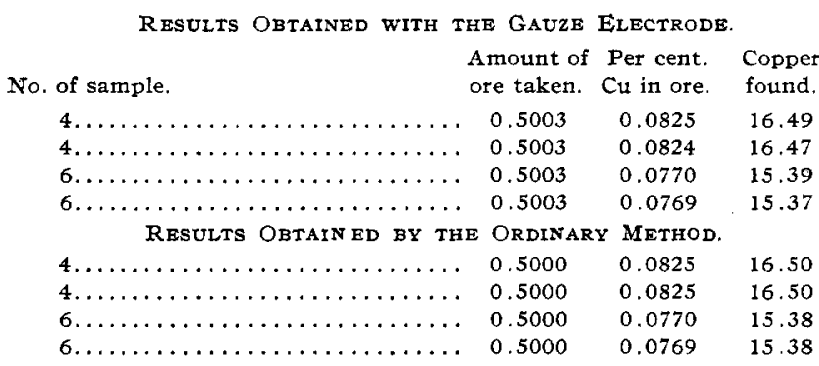

Process for Slags. - In case of slags and other low-grade material it is necessary to select a method of disintegration suited to the particular material in hand. Slags, which always give large quantities of gelatinous silica and contain low percentages of copper, give the most accurate results when disintegrated by means of nitric acid followed by hydrofluoric and sulphuric acids. After evaporation until heavy white fumes are evolved, the analysis is finished as in the process with ores. Redeposition is more frequently necessary with low-grade material than with high-, but in all cases it is more rapid, as well as more accurate, than filtering.

The following will illustrate the accuracy of the procedure:

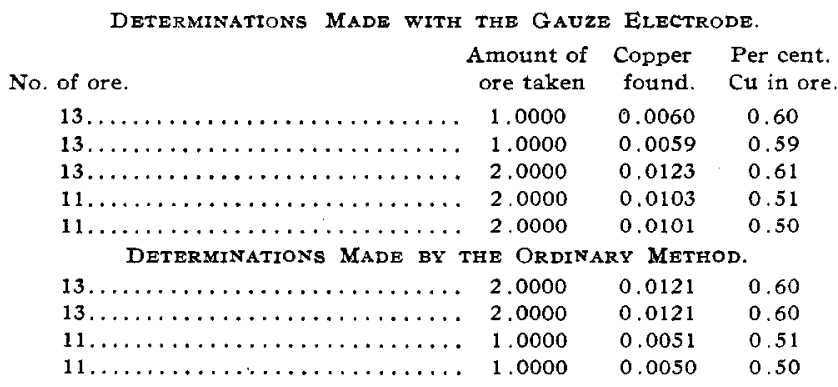

Elements which interfere, and at the same time are likely to occur in copper ores, are arsenic, antimony, lead and bismuth. The separation of antimony and bismuth from copper was tried under the preceding conditions but without success. Lead, in such quan- tities that it will deposit with the copper, is best removed as the sulphate. Arsenic, in small quantities, will not deposit with the copper, but in amounts about equivalent to the copper present begins to be deposited with the last of this. The following series of experiments, in which copper was deposited in the presence of varying amounts of arsenic, illustrates this point.

Arsenic taken.
0.0605
0.1210
0.1815
0.1210
0.2420

Copper taken.
0.2652
0.2751
0.2183
0.3038
0.2686
0.2028

Copper found.
0.2648
0.2747
0.2183
0.3035
0.3106
0.2026

All these depositions were made under the usual conditions. From these results it is seen that arsenic, when present in amounts large enough to contaminate the copper deposited, can easily be removed by dissolving the deposited copper and reprecipitating under the same conditions as, before. The removal of the interfering elements by chemical means can be accomplished by the following method:

The ore is disintegrated with nitric and hydrochloric acids, five or six cubic centimeters of sulphuric acid added and then it is evaporated until heavy white fumes of sulphuric anhydride are given off. It is now diluted to one hundred and fifty cubic centimeters with water, boiling to insure complete solution of the basic sulphate of iron (a few drops of hydrochloric acid are added if silver is present), filtered and washed with water containing a little sulphuric acid. The lead and silver remain on the filter paper. The filtrate is now heated to boiling and saturated with hydrogen sulphide, allowing the solution to cool during the process. The precipitated copper sulphide is filtered off and washed with water containing hydrogen sulphide. The precipitated sulphides are rinsed from the filter paper into a beaker using as little water as possible, warmed with a little colorless sodium sulphide to remove the antimony and arsenic and again passed through the same filter, being washed with water containing some sodium sulphide. Bismuth is now removed from copper by warming the mixed sulphides with a solution of potassium cyanide alkaline with ammonia. This dissolves the sulphide of copper leaving that of bismuth insoluble. The solution of the copper is boiled with nitric acid to destroy the potassium cyanide and electrolyzed in the usual manner.

UNIV. OF ARIZONA, TUCSON.

\section{THE EXACT DETERMINATION OF SULPHUR IN PYRITE AND MARCASITE.}

By E. T. ALLEN AND JOHN Johnston. Received March 8, 1910.

Technical chemists have regarded the determination of sulphur in pyrite, which serves as the starting point in the manufacture of vast quantities of sul- 